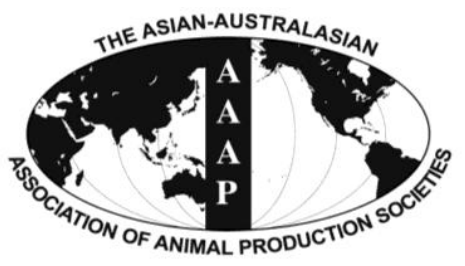

Asian-Aust. J. Anim. Sci.

Vol. 25, No. $10: 1457$ - 1465

October 2012

www.ajas.info

http://dx.doi.org/10.5713/ajas.2012.12187

\title{
Different Phosphate Transport in the Duodenum and Jejunum of Chicken Response to Dietary Phosphate Adaptation
}

\author{
Rejun Fang ${ }^{1, *}$, Zhifeng Xiang ${ }^{1,2}$, Manhu $\mathrm{Cao}^{1}$ and Jia $\mathrm{He}^{1}$ \\ ${ }^{1}$ College of Animal Science and Technology, Hunan Agricultural University, \\ Changsha, Hunan Province 410128, China
}

\begin{abstract}
Intestinal phosphate $(\mathrm{Pi})$ absorption across the apical membrane of small intestinal epithelial cells is mainly mediated by the type IIb Na-coupled phosphate co-transporter ( $\mathrm{NaPi}-\mathrm{IIb}$ ), but its expression and regulation in the chicken remain unclear. In the present study, we investigated the mRNA and protein levels of NaPi-Ilb in three regions of chicken small intestine, and related their expression levels to the rate of net phosphate absorption. Our results showed that maximal phosphate absorption occurs in the jejunum, however the highest expression levels of NaPi-IIb mRNA and protein occurs in the duodenum. In response to a low-Pi diet (TP $0.2 \%$ ), there is an adaptive response restricted to the duodenum, with increased brush border membrane (BBM) Na-Pi transport activity and $\mathrm{NaPi}$-IIb protein and mRNA abundance. However, when switched from a low- (TP $0.2 \%$ ) to a normal diet (TP $0.6 \%$ ) for $4 \mathrm{~h}$, there is an increase in BBM NaPi-Ilb protein abundance in the jejunum, but no changes in BBM NaPi-IIb mRNA. Therefore, our study indicates that $\mathrm{Na}$-Pi transport activity and $\mathrm{NaPi}$-IIb protein expression are differentially regulated in the duodenum vs the jejunum in the chicken. (Key Words: Chicken, NaPi-IIb, Small Intestine, Duodenum, Jejunum)
\end{abstract}

\section{INTRODUCTION}

Inorganic phosphate $(\mathrm{Pi})$ plays a major role in growth, development, bone formation and cellular metabolism. The kidney and the small intestine are important regulatory sites which maintain extracellular Pi concentrations. Sodiumcoupled phosphate transport is the major form of $\mathrm{Pi}$ absorption in both kidney and intestine. Phosphate uptake by renal and intestinal brush-border membrane vesicles (BBMVs) has been studied previously in human (Borowitz et al., 1989), rat (Ghishan et al., 1990), rabbit (Borowitz et al., 1992) and mouse (Nakagawa et al., 1994). The molecular basis of Pi uptake in kidney has been identified (sodium-phosphate $\left[\mathrm{Na}^{+}-\mathrm{Pi}\right]$ transporters types I and II) and well characterized. Type II $\mathrm{Na}^{+}-\mathrm{Pi}$ transporter is the major transport pathway of Pi reabsorption in kidney (Magagnin et al., 1993; Collins et al., 1994). However, intestinal absorption of Pi has drawn considerably less attention.

To date, two Na-dependent Pi cotransporters, type IIb

\footnotetext{
* Corresponding Author: Fang Rejun. Tel: +86-731-84618177, Fax: +86-731-84610280, E-mail: fangrj63@126.com

${ }^{2}$ College of Animal Science, Henan Institute of Science and Technology, Xinxiang, Henan Province 453003, China. Submitted Apr. 10, 2012; Accepted Jun. 2, 2012; Revised Jun. 24, 2012
}

(NaPi-IIb; GenBank accession number AAC80007) and type III Na/Pi cotransporter (also called PiT-2; GenBank accession number AF 196774), have been identified in mouse small intestine (Hilfiker et al., 1998; Bai et al., 2000). $\mathrm{Na} / \mathrm{Pi} \mathrm{IIb}$ is expressed in enterocytes and is located in BBMVs (Hilfiker et al., 1998). Apical location, kinetic characteristics, and $\mathrm{pH}$ dependency suggest that type IIb protein is likely a major $\mathrm{Na} / \mathrm{Pi}$ cotransporter in the mammalian intestine, this transporter is thought to be the rate-limiting step for trans-epithelial phosphate absorption (Murer et al., 2004).

Although the identification and characterization of a chicken homolog for the NaPi-IIb cotransporter has been extensively studied (Yan et al., 2007), the regulating mechanism of intestinal absorption of $\mathrm{Pi}$ in chickens has remain unknown. Earlier studies has shown that the dietary phosphate deprivation is an important physiological regulator of intestinal phosphate uptake as observed in BBM vesicles (BBMVs) in rats, mice, and pigs (Quamme, 1985; Hattenhaur et al., 1999; Kari et al., 2010). Kinetic parameters indicate increases in Na-dependent phosphate uptake are due to a $50 \%$ increase in maximal capacity for absorption (Vmax) with no change in affinity, indicating the maximal capacity for phosphate transport is increasing and not the affinity of NaPi-IIb transporter for phosphate 
(Segawa et al., 2004). The increase in Vmax in mice fed a low-P diet has been accompanied by an increase in abundance of membrane-bound NaPi-IIb cotransporter protein in the small intestine (Hattenhaur et al., 1999; Segawa et al., 2004). However, mixed results have been reported on the effect of low-P diets on NaPi-IIb mRNA expression and it appears to be dependent upon both the severity and length of dietary Pi deprivation.

The severity of dietary $\mathrm{Pi}$ restriction in rodent studies raised questions as to whether the $\mathrm{NaPi}$-IIb is an important factor under physiologically relevant situations (Knochel et al., 1996; Heaney et al., 2002). However, severe Pi deprivation is often conducted without consideration for the intestinal segments of Pi absorption. Huber et al. (2002) indicated that at least two different mechanisms were involved in goat intestinal $\mathrm{Pi}$ absorption between the duodenum and the jejunum. Additionally, the distribution of transporters is different along the intestinal axis from proximal to distal segments and from the crypt to villus in chickens (Yan et al., 2007). In an attempt to determine the mechanism through which dietary $\mathrm{Pi}$ regulates intestinal $\mathrm{P}$ absorption, diets almost devoid of $\mathrm{Pi}(<10 \%$ of the total $\mathrm{P}$ (tPi) requirement), excess of $\mathrm{Pi}(>10 \%$ of the total $\mathrm{Pi}(\mathrm{tPi})$ requirement) and adapting from devoid $\mathrm{Pi}$ to excess $\mathrm{Pi}$ were utilized in the present chicken experiments. Our objectives were to determine whether modest reductions or adaption in dietary $\mathrm{Pi}$ results in stimulation of $\mathrm{Na}$-dependent phosphate transport, mRNA expression and protein levels of NaPi-IIb in the distinct segments of chicken small intestine.

\section{MATERIALS AND METHODS}

\section{Animals and diets}

All animal work was approved by the University of Hunan Agricultural Animal Care Committee (Changsha, Hunan Province, China). To determine the effects of dietary $\mathrm{Pi}$ on the expression of the chicken intestinal Na-Pi cotransporter, experimental diets were formulated to be deficient in total Pi. A total of ninety 40-d-old Ross broilers with an average initial weight of about $1.5 \mathrm{~kg}$ were allotted to three treatments randomly, each treatment had five replicates of six broilers. Levels of dietary phosphorus were: low (TP $0.2 \%$ ) Pi, normal (TP 0.6\%) Pi, high (TP $1.0 \%) \mathrm{Pi}$. These diets were formulated based on a corn and soybean meal mash basal diet formulated to meet NRC (1994) broiler requirements and China broiler standard (Table 1). In the chronic adaptation studies, the chickens were fed the different Pi diets ad libitum for $7 \mathrm{~d}$. In the acute adaptation studies, the chickens were fed the $0.2 \% \mathrm{Pi}$ diet for $4 \mathrm{~h}$ in the morning for 7 consecutive days. On the day of the experiment, the chickens were fed the $0.2 \%$ or $1.0 \% \mathrm{Pi}$ diet for $4 \mathrm{~h}$ before the experiments. Normal drinking water was supplied ad libitum.
Table 1. Composition and nutrient levels of diets

\begin{tabular}{lccc}
\hline Ingrendients (\%) & Low Pi & Normal Pi & Higher Pi \\
\hline Maize & 60 & 56.2 & 54.1 \\
Soybean meal & 28.5 & 28.5 & 28.2 \\
Fish meal & 3.0 & 3.0 & 3.0 \\
Colza oil & 3.5 & 4.5 & 5.0 \\
Met & 0.1 & 0.1 & 0.1 \\
Limestone & 0.5 & 1.3 & 1.6 \\
Dicalcium phosphate & 0 & 2.0 & 3.5 \\
Salt & 0.4 & 0.4 & 0.4 \\
Premix & 4.0 & 4.0 & 4.0 \\
Nutrient levels & & & \\
$\quad$ ME (MJ/kg) & 12.66 & 12.55 & 12.59 \\
CP (\%) & 19.38 & 19.08 & 19.01 \\
Lys (\%) & 1.08 & 1.07 & 1.07 \\
Met (\%) & 0.44 & 0.43 & 0.43 \\
Met+cys (\%) & 0.69 & 0.67 & 0.67 \\
Ca (\%) & 0.41 & 1.22 & 1.62 \\
Total P (\%) & 0.43 & 0.82 & 1.48 \\
Available P (\%) & 0.21 & 0.61 & 1.02 \\
\hline
\end{tabular}

${ }^{a}$ Premix provided the following per kilogram of diet: vitamin A 10,000 $\mathrm{IU}$; vitamin $\mathrm{D}_{3} 2,750 \mathrm{IU}$; vitamin $\mathrm{E} 20 \mathrm{IU}$; vitamin $\mathrm{K}_{3} 2 \mathrm{mg}$; vitamin $\mathrm{B}_{1}$ $1.5 \mathrm{mg}$; riboflavin $6 \mathrm{mg}$; pantothenic acid $12 \mathrm{mg}$; niacin $20 \mathrm{mg}$; vitamin $\mathrm{B}_{6} 2.5 \mathrm{mg}$; vitamin $\mathrm{B}_{12} 12 \mu \mathrm{g}$; choline $500 \mathrm{mg}$; $75 \mathrm{mg}$; Zn $75 \mathrm{mg}$; Fe $95 \mathrm{mg}$; Cu $10 \mathrm{mg}$; I $0.6 \mathrm{mg}$; Se $0.3 \mathrm{mg}$.

\section{Isolation of brush border membrane vesicles (BBMVs)}

The methods used to prepare intestinal BBMVs have been described previously (Hector Giral et al., 2009). The purity of the membranes was assessed by measuring the levels of leucine amino peptidase, $\mathrm{Na}^{+}, \mathrm{K}^{+}$-ATPase and cytochrome c oxidase (Palmada et al., 2004). Ross broilers $(1.5 \mathrm{~kg})$ were euthanized with an intraperitoneal injection of $60 \mathrm{mg} / \mathrm{kg}$ pentobarbitone sodium ((Pentoject, Animalcare Ltd, York, UK) before removal of the distinct regions of the small intestine. Intestinal segments were opened longitudinally, and the mucosa scraped off using glass slides. The resulting mucosa was suspended in buffer containing (in mmol/L): 50 mannitol, 2Hepes ( $\mathrm{pH} 7.1$ ) and 0.25 phenylmethylsulphonyl fluoride (PMSF), and homogenized three times at half-speed for $20 \mathrm{~s}$ using a Ultra Turrax homogenizer (VWR, lutterworth, Leicestershire, UK), followed by the addition of $\mathrm{MgCl}_{2}$ to a concentration of $10 \mathrm{mmol} / \mathrm{L}$, and then stirred on ice for $20 \mathrm{~min}$. The suspension was then centrifuged at 3,000 $\mathrm{g}$ for $20 \mathrm{~min}$, and the supernatant then re-centrifuged at 27,000 $\mathrm{g}$ for $30 \mathrm{~min}$. The pellet was suspended in buffer containing (in $\mathrm{mmol} / \mathrm{L}$ ): 300 mannitol, 20Hepes, $0.1 \mathrm{MgSO}_{4}(\mathrm{pH} 7.2)$ and 0.25 PMSF, by passing six times through a 21 gauge needle. The suspension was then centrifuged for $15 \mathrm{~min}$ at $6,000 \mathrm{~g}$, and the resulting supernatant centrifuged at 27,000 $\mathrm{g}$ for a further $30 \mathrm{~min}$. The purified BBMVs pellet was finally resuspended in the same buffer to a protein concentration of 
3 to $6 \mathrm{mg} / \mathrm{ml}$ using five or six passes through a 21 gauge needle. All steps were carried out at $4^{\circ} \mathrm{C}$.

\section{${ }^{32} \mathbf{P}$ uptake into isolated BBMVs}

$\mathrm{Pi}$ transport was measured by radioactive ${ }^{32} \mathrm{Pi}$ uptake in freshly isolated BBMVs. ${ }^{32} \mathrm{Pi}$ uptake of intestinal BBMVs was measured as previously described (McHaffie GS et al., 2007). Briefly, $10 \mu \mathrm{l}$ of isolated BBMVs prewarmed to $37^{\circ} \mathrm{C}$ were incubated with $40 \mu \mathrm{l}$ of uptake buffer $(150 \mathrm{mM}$ $\mathrm{NaCl}, 16 \mathrm{mM}$ HEPES (pH 7.5), and $0.1 \mathrm{mM} \mathrm{K}_{2} \mathrm{HPO}_{4}$ ) containing $\mathrm{K}_{2} \mathrm{H}^{32} \mathrm{PO}_{4}$ tracer. After $30 \mathrm{~s}$ of incubation at $37^{\circ} \mathrm{C}$, uptake buffer was quickly removed by rapid Millipore filtration and washed with ice-cold stop solution (100 mM NaCl, $100 \mathrm{mM}$ mannitol, and $5 \mathrm{mM}$ HEPES, $\mathrm{pH}$ 7.5). The incorporation of ${ }^{32} \mathrm{Pi}$ was measured in a beta counter. The Na-dependent uptake of Pi was calculated as the difference between the incorporation of ${ }^{32} \mathrm{Pi}$ in the presence and absence of $\mathrm{NaCl}$.

\section{Western blot analysis}

Polyclonal antibodies for NaPi-IIb were raised in female New Zealand white rabbits against a synthetic peptide (CKNLEEEEKEQDVPVKAS) corresponding to the amino acids 644-661 residues of the C-terminus of the chicken $\mathrm{NaPi}$-IIb protein (GenBank accession number AF AF29887). The methods used to develop antibodies have been described previously (Ramziya Kiyamova et al., 2008). For western blotting, samples (50 $\mu \mathrm{g}$ of intestinal BBMV) were separated on $10 \%$ SDS/PAGE gels, transferred to PVDF membranes and incubated overnight with antibodies against NaPi-IIb $(1: 3,000)$ and $\beta$-actin $(1: 10,000)$. After several washes, membranes were incubated for $2 \mathrm{~h}$ at room temperature with HRP-linked secondary antibodies (cat no.; NA931V, GE Healthcare) followed by incubation with a chemiluminescence reagent (ECL, Amersham Pharmacia Biotech). Immunoreactive signals were detected using the DIANA III-chemiluminescence detection system (Raytest, Straubenhardt, Germany) and quantification was performed with AIDA software (Advanced Image Data Analyser AIDA, Raytest). Data are shown as ratios between the protein of interest to $\beta$-actin.

\section{Real-time PCR}

Total RNA was extracted from mucosal scrapes of the distinct regions of the chick small intestine using a QIAamp RNA blood mini kit according to the manufacturer's instructions (Qiagen, Crawley, UK). RNA was reverse transcribed with $0.5 \mu \mathrm{g}$ of oligo-dT primer and a First Strand cDNA synthesis kit (Superscript II RNase H-reverse transcriptase; Life Technologies, Paisley, UK). Using QuantiTech SYBR ${ }^{\circledR}$ Green PCR kit (Qiagen) on a LightCycler Real-Time PCR instrument (version 3.5, Roche
Diagnostics, Lewes, UK), we determined mRNA levels using the following primers: NaPi-IIb [5'GAAAGTGGTGAAGATGCC-3' (forward) and (reverse) 5'- AAGTATGAGACCGATGGC -3'], $\beta$-actin [5'-CAGCC ATCTTTCTTGGGTAT-3' (forward) and (reverse) 5'-GTTT AGAAGCATTTGCGGTG-3']. For all primers, cycling conditions were as follows: $95^{\circ} \mathrm{C}$ for $10 \mathrm{~min}$ followed by 45 cycles of $95^{\circ} \mathrm{C}$ for $15 \mathrm{~s}, 60^{\circ} \mathrm{C}$ for $20 \mathrm{~s}$ and $72^{\circ} \mathrm{C}$ for $40 \mathrm{~s}$ with transition rates of $20^{\circ} \mathrm{C} / \mathrm{s}$ and a single fluorescence acquisition at $81^{\circ} \mathrm{C}$. A standard curve for each gene was established by performing the above procedure with serially diluted DNA samples of known concentrations. The relative amounts of the target and reference genes in each sample were then calculated based on the crossing-point analysis (Relquant, version 1.01, Roche Diagnostics); the second derivative maximum method was used to automatically determine the crossing point for individual samples. The sequences of the PCR products were confirmed by DNA sequencing.

\section{Statistics}

All data (means \pm SD) were tested for significance by applying the unpaired Student's t-test and ANOVA. Differences at the level of $p<0.01$ and $p<0.05$ were considered as significant.

\section{RESULTS}

\section{Expression of NaPi-IIb in distinct regions of the chicken small intestine}

The profile of phosphate absorption and the expression of NaPi-IIb mRNA and protein along three distinct intestinal regions of the chicken small intestine were examined using the following landmarks: duodenum (from distal of the gizzard to $1 \mathrm{~cm}$ distal of the bile duct), jejunum (1 cm distal from the bile duct to the Meckel's diverticulum), and ileum (Meckel's diverticulum to $5 \mathrm{~cm}$ proximal to the ileocecal junction). In normal dietary $\mathrm{Pi}$ levels (TP 0.6\%), Pi uptake measurements of intestinal BBMV showed that Na-dependent $\mathrm{Pi}$ activity was significantly higher in the jejunum than in the ileum and duodenum (Figure 1A), with the latter two regions having the ability to absorb equivalent amounts of phosphate. Quantification of NaPi-IIb mRNA expression in the chicken small intestine using real-time PCR demonstrated that the transcript for this protein is expressed at highest levels in the duodenum followed by the jejunum and the ileum (Figure 1B). The protein levels of NaPi-IIb were examined using Western blotting of intestinal BBM vesicles isolated from the distinct regions of the chicken small intestine. The ratio of this protein to $\beta$-actin enabled us to access the regional distribution of the sodium-phosphate co-transporter. 


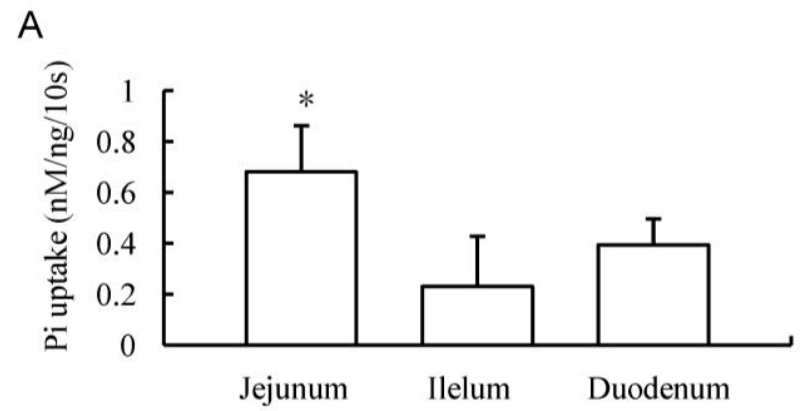

B

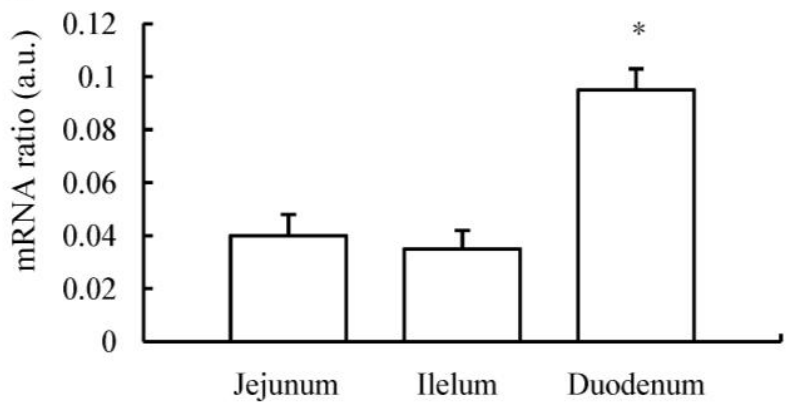

C

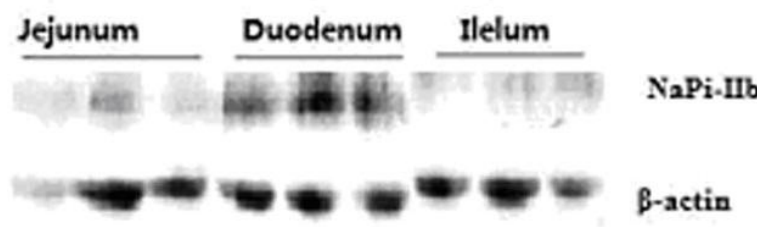

D

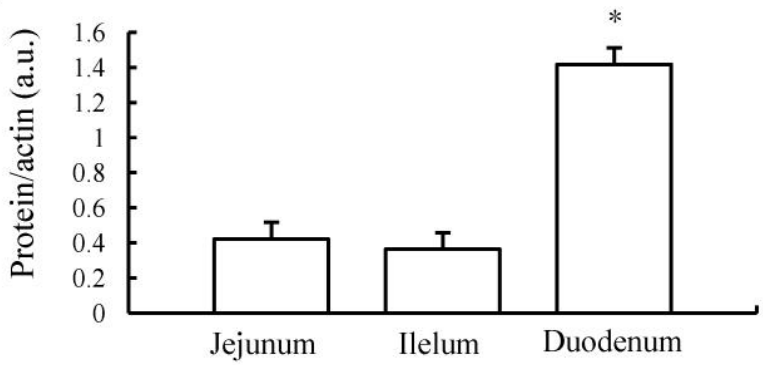

Figure 1. Expression profile of $\mathrm{NaPi}$ transport activity, protein, and mRNA along the small intestine of chickens fed the $0.6 \% \mathrm{Pi}$ diet ad libitum. (A) brush border membrane (BBM) vesicle (BBMV) Na-dependent Pi uptake activity in small intestinal segments. (B) NaPi-IIb mRNA abundance determined by RT-PCR in chicken intestinal segments. (C) Western blot analysis of NaPiIIb protein in distinct regions of the chicken small intestine. (D) Quantification of $\mathrm{NaPi}$-IIb protein relative to $\beta$-actin. a.u., arbitrary units. ${ }^{*} \mathrm{p}<0.05$.

In accordance with the in vivo uptake data and the mRNA expression profile, quantification of $\mathrm{NaPi}$-IIb protein in relation to $\beta$-actin protein levels revealed that the transporter was most abundant in the duodenum and that lower levels were evident in the jejunum and in the ileum (Figure 1C and 1D).
Effects of dietary $\mathrm{Pi}$ restriction on regulation of intestinal Na-Pi transporter activity, protein and Mrna

Intestinal BBMV were isolated from chickens chronically fed the $0.2,0.6$, or $1.0 \% \mathrm{Pi}$ diets. Pi uptake activity was determined in BBMV isolated from the duodenum, the jejunum and the ileum. Duodenal BBMV isolated from birds chronically fed the low-Pi $(0.2 \%)$ diet showed a $68 \%$ increase in the Na-dependent $\mathrm{Pi}$ uptake compared with BBMV isolated from the birds fed the normal-Pi (0.6\%) or high-Pi (1.0\%) diet (Figure 2). However, there were no significant differences in the jejunal and ileac BBMV Pi transport activity among the
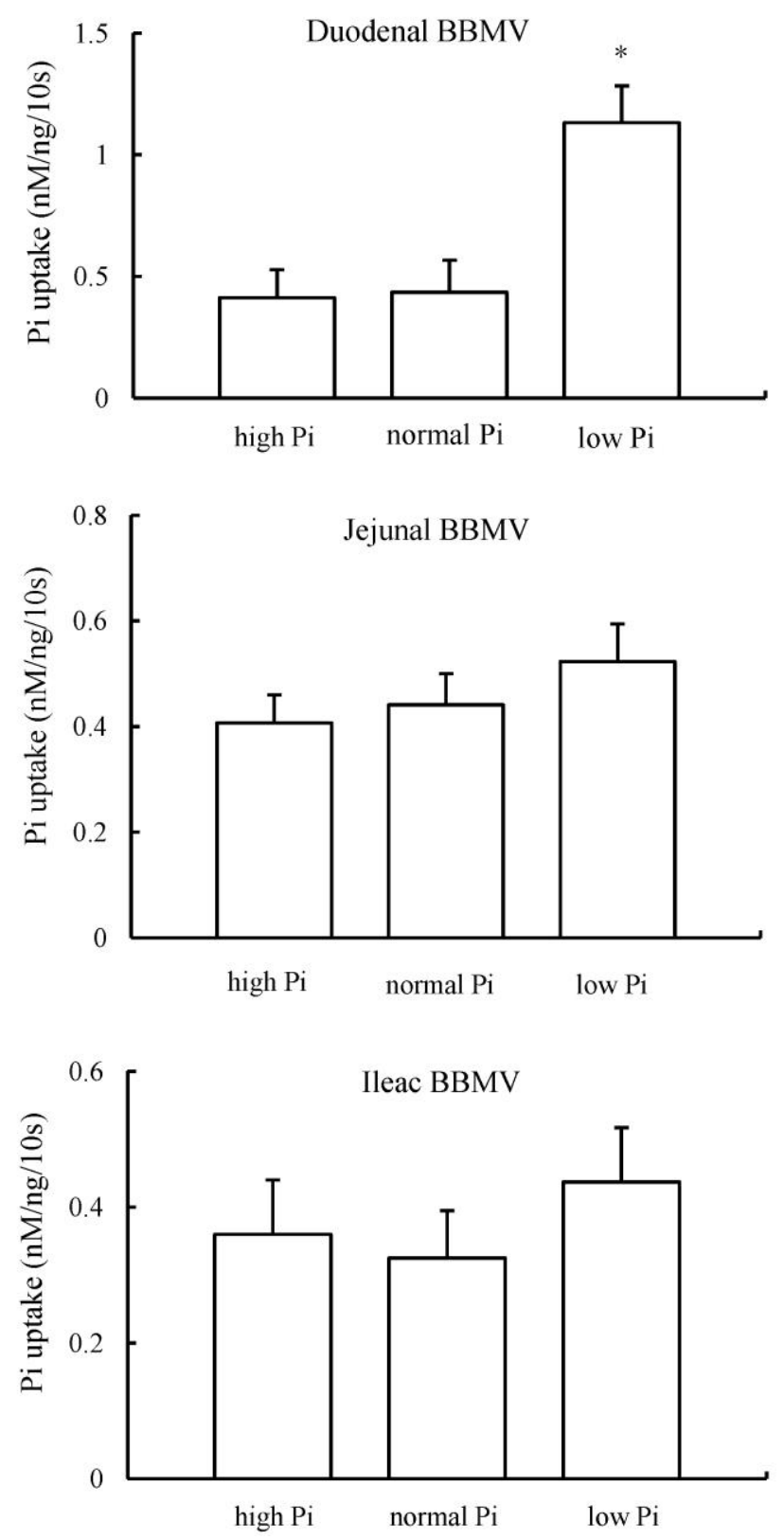

Figure 2. Effects of dietary $\mathrm{Pi}$ on chicken intestinal BBMV Pi transport activity. NaPi transport uptake was measured in BBMV of duodenum, ileum and jejunum of chickens chronically fed highPi (1.0\%), normal Pi (0.6\%), or low-Pi (0.2\%) diet. * $\mathrm{p}<0.05$. 
three Pi diets (Figure 2).

$\mathrm{NaPi}-\mathrm{IIb}$ levels were determined in BBMV isolated

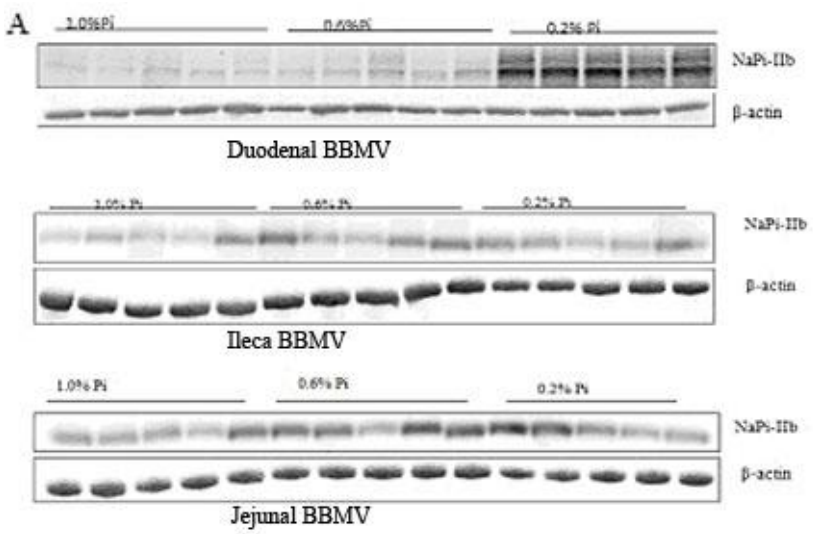

B
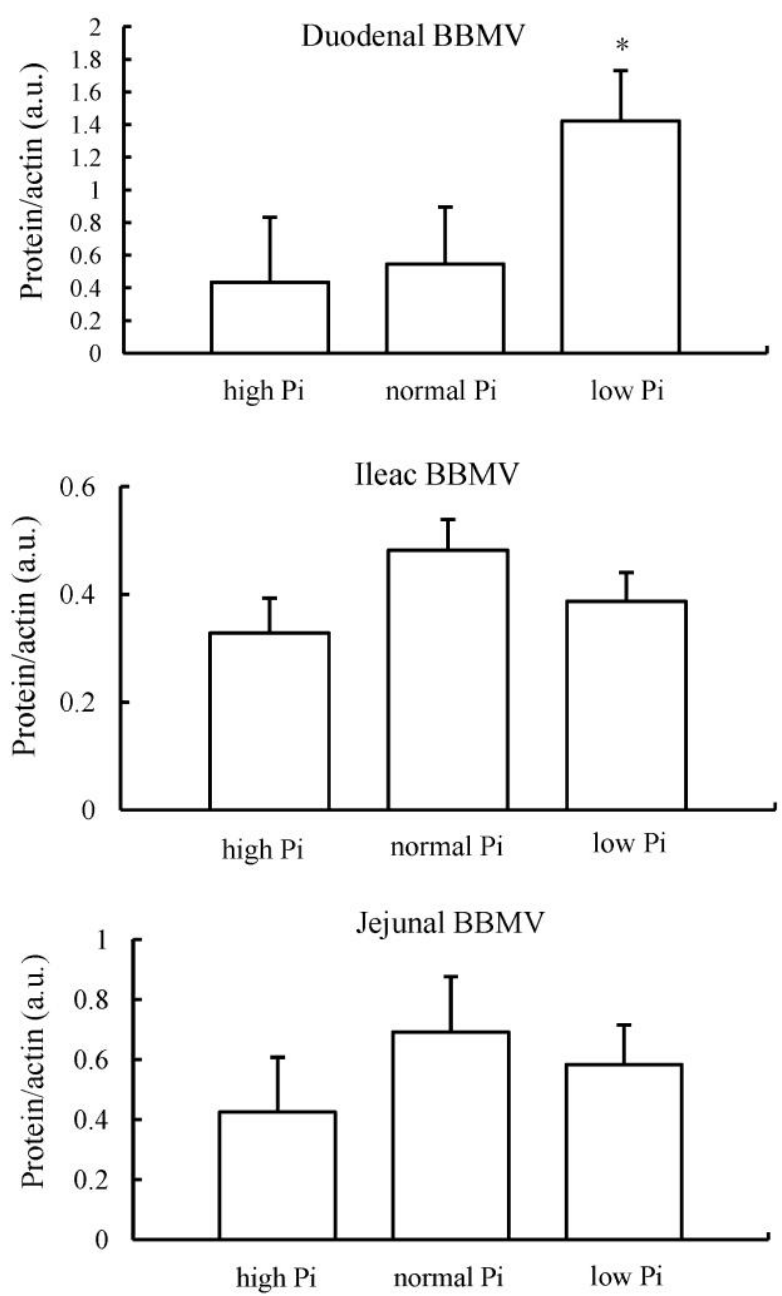

Figure 3. BBMV NaPi-IIb protein regulation in chickens chronically fed high-, normal-, or low-Pi diet. (A) detection of $\mathrm{NaPi}-\mathrm{Ill}$ protein by Western blots analysis in BBM vesicles prepared from intestinal mucosa of chicken duodenum, jejunum and ileum. (B) quantification of $\mathrm{NaPi}-\mathrm{IIb}$ protein relative to $\beta$ actin, results is expressed as the means \pm SEM of Western blots. The abundance of $\mathrm{NaPi}-\mathrm{IIb}$ is given as a ratio of $\mathrm{NaPi}$-IIb protein to $\beta$-actin protein, in a.u.. $* \mathrm{p}<0.05$. from three distinct regions of the chicken small intestine by Western blotting. Jejunal and ileac BBM did not show significant changes in NaPi-IIb expression (Figure 3A). However, BBM isolated from the duodenum fed the $0.2 \%$ $\mathrm{Pi}$ diet showed an up-regulation of $\mathrm{NaPi}$-IIb total protein expression (Figure 3B).

Quantification of mRNA levels of the Na-Pi cotransporters showed a significant increase of $\mathrm{NaPi}-\mathrm{IIb}$ mRNA levels in the ileum of chickens fed the $0.2 \%$ Pi diet. This implies that chronic adaptation to the low-Pi diet is at least in part mediated by transcriptional mechanisms (Figure 4).

\section{Changes of NaPi-IIb protein and mRNA levels when} adapted low-Pi diet to normal Pi diet for $4 \mathrm{~h}$

For these studies, chickens were trained to eat their diets for $7 \mathrm{~d}$. On the 8 th day, chickens that were chronically
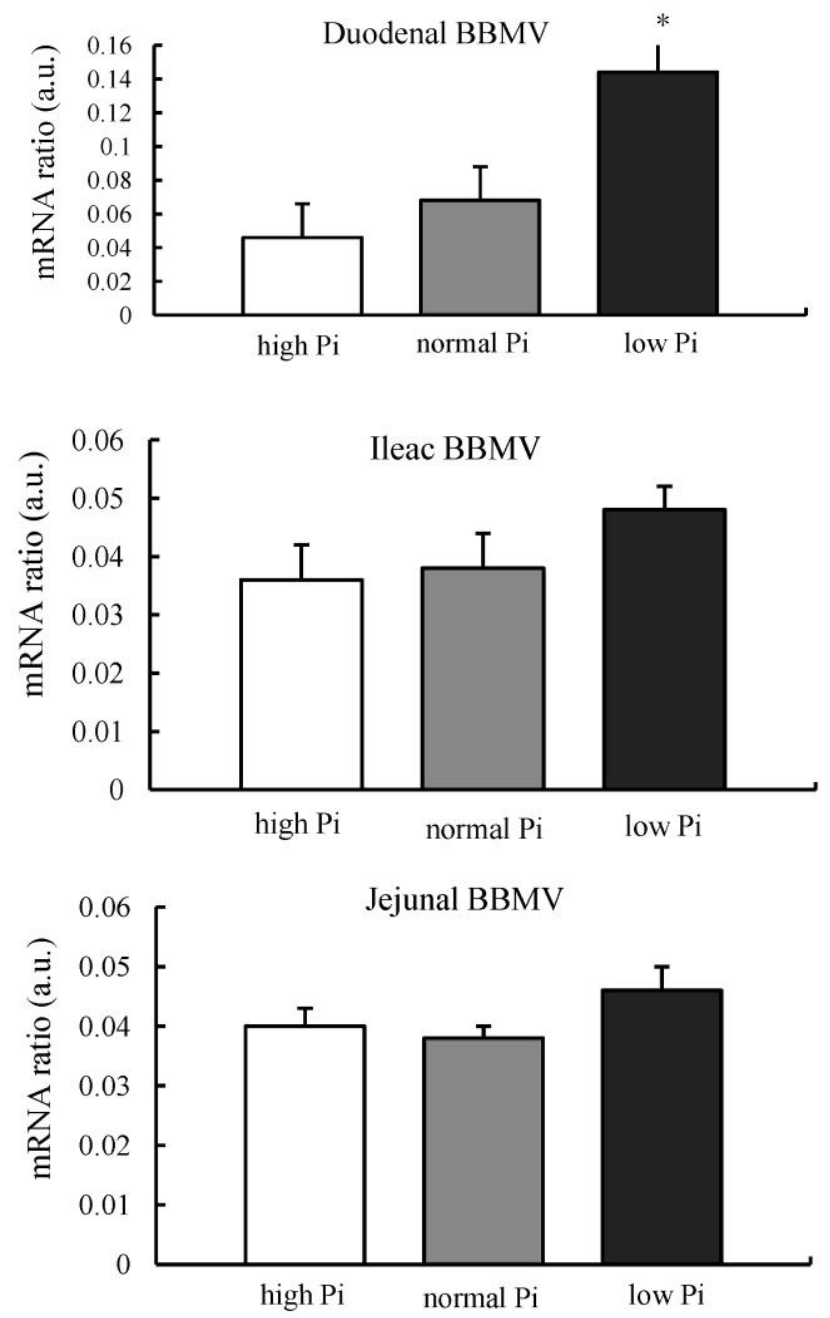

Figure 4. Chicken intestinal NaPi-IIb mRNA regulation chronically fed high-, normal-, or low Pi diet. In duodenum, NaPiIIb mRNA abundance is increased in parallel with increases in BBMV NaPi-IIb protein abundance and Pi uptake in response to chronic low-Pi diet. There are no changes in jejunal or ileac NaPiIIb mRNA abundance in response to low-Pi diet. $* \mathrm{p}<0.05$. 
adapted on a low-Pi diet were fed acutely a normal-Pi diet for $4 \mathrm{~h}$. In BBMV isolated from the jejunum, there was a fivefold increase in the $\mathrm{Pi}$ uptake rate when the chickens were switched from a chronic low-Pi to an acute high-Pi diet. In contrast, in BBMV isolated from the duodenum, there was no change in Pi uptake under the same conditions, indicating a regulatory adaptation different from that in chronic conditions (Figure 5).

The increase in BBMV Pi uptake in the jejunum was associated with an increase in $\mathrm{NaPi}$-IIb protein abundance (Figure 6A and 6B). There were no changes in NaPi-IIb protein abundance in BBM isolated from the duodenum, and also there were no changes in NaPi-IIb mRNA abundance in the duodenum or jejunum (Figure 7).

\section{DISCUSSION}

Dietary phosphate deprivation is an important physiological regulator of intestinal phosphate absorption. Previously, in a series of studies with rodent species, dietary $\mathrm{Pi}$ restriction acutely and chronically increased intestinal NaPi-IIb transporter expression (Cross et al., 1990; Hattenhauer et al., 1999, Segawa et al., 2004). Similar responses have been reported in goats, humans and fishes (Huber et al., 2002; Sugiura et al., 2007; Villa-Bellosta et al., 2010). In our study, the reduction of Pi in the diet had a significant effect on the Pi uptake and the expression of the
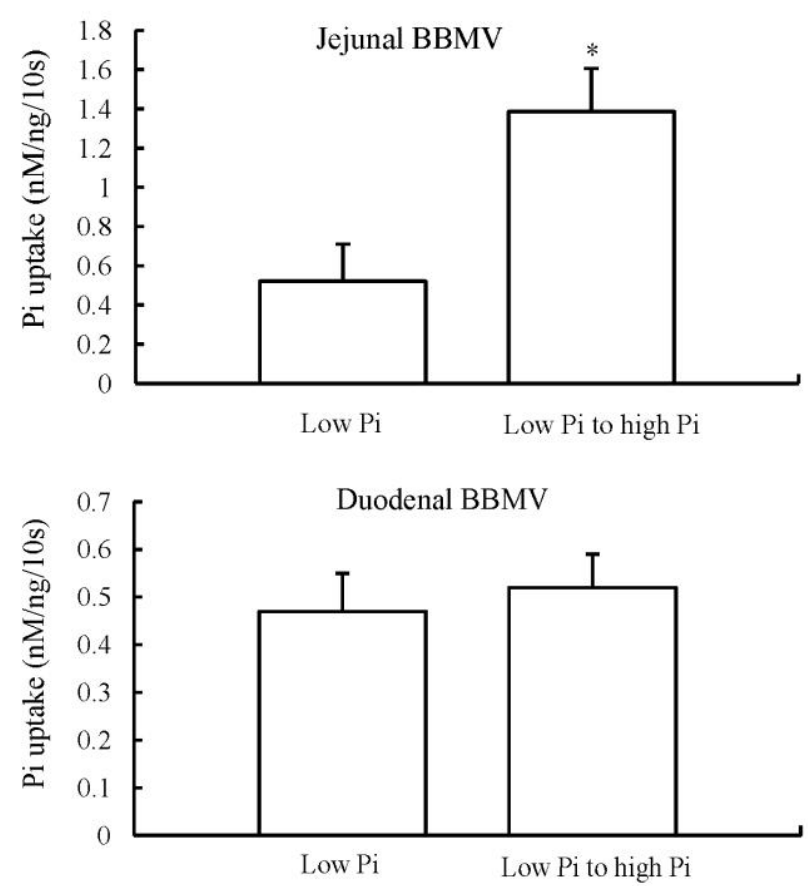

Figure 5. Na-dependent $\mathrm{Pi}$ uptake in BBMV of chickens chronically adapted to a low-Pi diet and then fed low- to high-Pi diet for $4 \mathrm{~h}$. Jejunal BBMV shows an increased $\mathrm{NaPi}$ transport activity. Whereas duodenal BBMV demonstrates no significant changes in NaPi transport activity. ${ }^{*} \mathrm{p}<0.05$.
Na-Pi cotransporter by stimulating increase in the mRNA levels only in the duodenum. However, in mice it was shown that significant increases of NaPi-IIb mRNA abundance in duodenum, jejunum, and ileum when fed low$P$ diet for 5 d. Furthermore, Hattenhauer et al. (1999) saw $\mathrm{NaPi}-\mathrm{IIb}$ protein and Pi transport were both increased across all segments of the intestine by dietary $\mathrm{P}$ restriction in mice after $5 \mathrm{~d}$ of feeding with low-P diet, although there was not any increase of NaPi-IIb mRNA. In rat, the NaPi-IIb transporter was found to be increased from duodenum to ileum when fed a low-P diet compared to fed an adequate-P diet. It is unclear why the broiler NaPi-IIb cotransporter

A

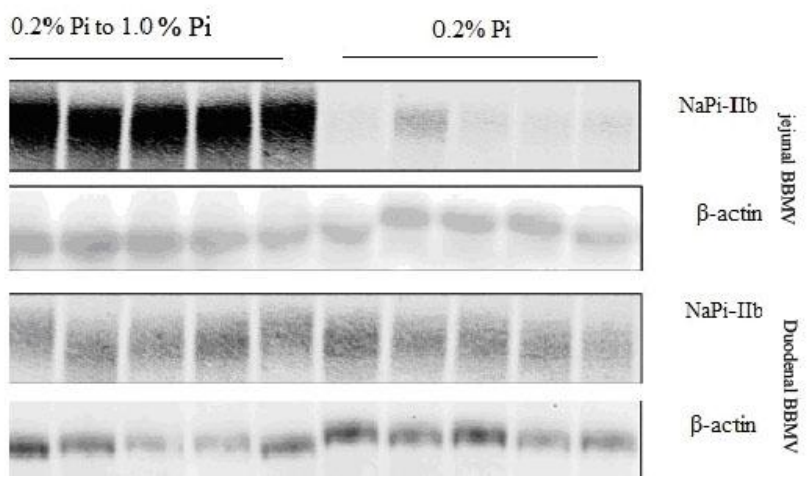

\section{B}
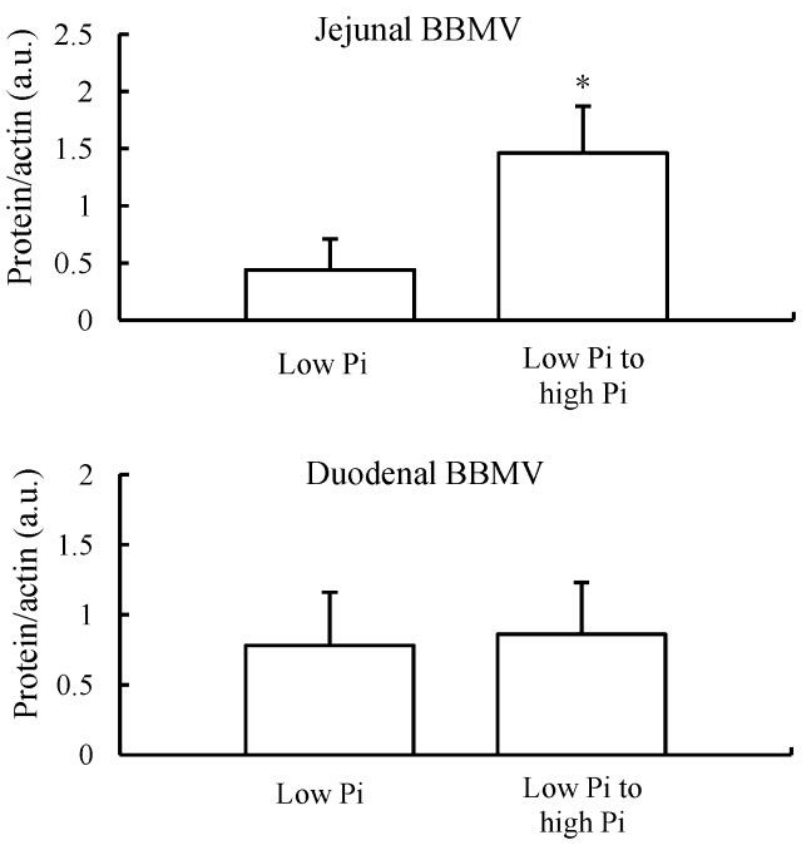

Figure 6. NaPi-Ilb protein regulation in chickens chronically adapted to low-Pi diet and then fed low- or high-Pi diet for $4 \mathrm{~h}$. (A) detection of NaPi-IIb protein by Western blots analysis in chicken duodenum and jejunum BBMV. (B) quantification of $\mathrm{NaPi}$-IIb protein relative to $\beta$-actin. There is a significant increase in jejunal BBMV NaPi-IIb protein abundance. No significant changes in NaPi-IIb protein in duodenal BBMV. $* \mathrm{p}<0.05$. 

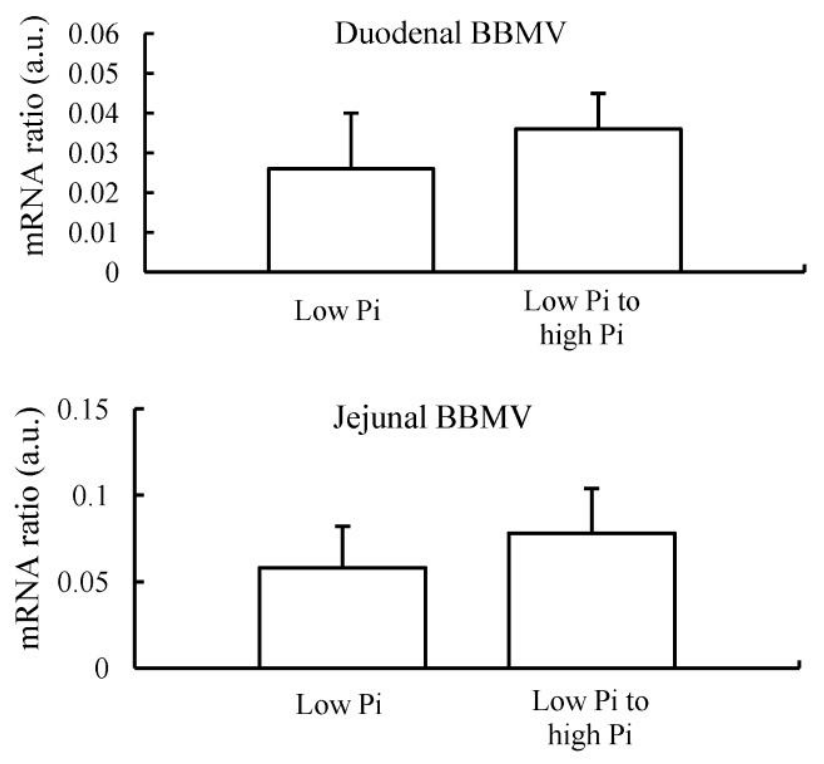

Figure 7. NaPi-IIb mRNA regulation in chicken small intestine when chronically adapted to low-Pi diet and then fed low- or high$\mathrm{Pi}$ diet for $4 \mathrm{~h}$. There are no significant changes in $\mathrm{NaPi}-\mathrm{IIb}$ mRNA levels both duodenal BBMV and jejunal BBMV in response to acute changes in dietary $\mathrm{Pi}$.

expression was found not to be increased with dietary $\mathrm{P}$ restriction in as many segments as it is in rodent species. It is possibly due to the specific length and the movement of nutrients through different segments of small intestine. However, it appears that the severity of dietary restriction, and length of time over which restriction is imposed may affect the mechanism though which intestinal Na-dependent phosphate uptake is stimulated.

In this study, we found that the chicken small intestine has the ability to absorb phosphate in all segments examined, with the highest $\mathrm{NaPi}-\mathrm{IIb}$ protein expression in the BBMVs of chicken duodenum under normal dietary Pi. This finding is in agreement with a previous study that showed the highest NaPi-IIb mRNA expression in chicken duodenum as well (Miyamoto et al., 1995). However, it was surprising that BBMVs Na-Pi co-transport activity was highest in the jejunum, despite lower NaPi-IIb protein and mRNA expression than in the duodenum. The equilibrium values of $\mathrm{Pi}$ uptake determined in duodenal and jejunal BBMVs under three different dietary Pi levels were very similar, suggesting that this discrepancy was not induced by differences in intravascular space/total protein rates. Posttranslational modification of NaPi-IIb protein and/or the presence of additional $\mathrm{Na}-\mathrm{Pi}$ transporters playing different roles in the duodenum and the jejunum could explain the discrepancy between $\mathrm{Na}-\mathrm{Pi}$ co-transport activity and NaPi-IIb protein expression. Posttranslational modifications of $\mathrm{NaPi}$-IIb described in previous studies include glycosylation (Arima et al., 2002), ubiquitination
(Xu et al., 2002), and palmitoylation (Hashimoto et al., 2000). However, the role of these modifications in modulation of the activity or trafficking of the intestinal NaPi transporters needs to be determined.

The jejunum has been considered to be the major site for Pi absorption in chicks (Hurwitz et al., 1970; Blahos et al., 1981). The duodenum, however, may have a greater ability to absorb Pi than the jejunum, but its short length and short transit time of digesta through the duodenum possibly limits its role in chicken intestinal $\mathrm{Pi}$ absorption (Yan et al., 2007). Our studies involved in the regulation of $\mathrm{NaPi}$-IIb with dietary Pi deprivation showed that jejunal BBMV NaPi intake activity is increased, when birds adapted to a chronic low-Pi $(0.2 \%)$ for $7 \mathrm{~d}$ compared with animals adapted to high-Pi $(1.0 \%)$ diets. The increase in $\mathrm{NaPi}$ transport activity is associated with parallel increases in $\mathrm{NaPi}$-IIb protein and mRNA in the jejunum. In contrast, no significant response is observed in ileac and duodenal BBMV. The increase in Na-dependent Pi transport activity in the jejunum after dietary $\mathrm{Pi}$ restriction treatment is paralleled to the increase in NaPi-IIb protein and mRNA levels, suggesting that the increase induced by low-Pi regulation likely involves the synthesis of new $\mathrm{NaPi}-\mathrm{IIb}$ mRNA in the jejunum. This finding indicates that the effect of chronically dietary $\mathrm{Pi}$ regulation on chicken jejunal NaPiIIb gene expression can be mediated by increased transcriptional activation.

In contrast, birds fed a low-Pi diet for $7 \mathrm{~d}$ and then acutely adapted to a high-Pi diet for $4 \mathrm{~h}$ shows an unexpected significantly increase in jejunal BBMV NaPi transport activity associated with a parallel increase in jejunal BBMV NaPi-IIb protein abundance. However, there are no significant changes in duodenal BBMV NaPi transport activity and $\mathrm{NaPi}-\mathrm{IIb}$ protein expression. More interestingly, there were no significant changes in the jejunal and duodenal BBMV NaPi-IIb mRNA abundance in response to acutely dietary $\mathrm{Pi}$ adaptation. This inconsistency might be a consequence of regional differences in the stability of the mRNA, or the rate of translation and/or degradation of the protein, or might relate to differences in post-translational modification or the intrinsic activity of the protein in the different segments of the small intestine.

In summary, we determined the protein expression of the NaPi-IIb in the apical membrane of chicken enterocytes. $\mathrm{NaPi}$-IIb plays a major role in the adaptation to chronic and acute alterations in dietary phosphate. The dietary adaptation of NaPi-IIb in the duodenum is different from that in the jejunum, suggesting different regulatory mechanisms. Although the duodenum seems to play a more important role in the chronic adaptation to a low-Pi diet, the jejunum plays a major role in the acute response to a highPi diet. 


\section{ACKNOWLEDGEMENTS}

This research was supported by grants from the National Natural Science Foundation of China (No.31172218), National Scientific and Technological Supporting Project (No. 2011BAD26B03), the Program for Science and Technology Innovative Research Team in Higher Educational Institutions of Hunan Province. Thanks also be given to Dr. Zhai Hengxiao from Purdue University of America for his kindness revised of this manuscript.

\section{REFERENCES}

Arima, K., E. R. Hines, P. R. Kiela, J. B. Drees, J. F. Collins and F. K. Chishan. 2002. Glucocorticoid regulation and glycosylation of mouse intestinal type IIb Na-Pi cotransporter during ontogeny. Am. J. Physiol. Gastrointest. Liver Physiol. 283:G426-G434.

Bai, L., J. F. Collins and F. K. Ghishan. 2000. Cloning and characterization of a type III Na-dependent phosphate cotransporter from mouse intestine. Am. J. Physiol. Cell Physiol. 279:C1135-C1143.

Blahos, J. and A. D. Care. 1981. The jejunumis the site of maximal rate of intestinal absorption of phosphate in chicks. Physiol. Bohemoslov. 30:157-159.

Borowitz, S. M. and F. K. Ghishan. 1989. Phosphate transport in human jejunal bnrsh border membrane vesicles. Gastroenterology 96:4-10.

Borowitz, S. M. and G. S. Granrud. 1992. Ontogency of intestinal phosphate absorption in rabbits. Am. J. Physiol. 262:G847G853.

Collins, J. F. and F. K. Ghishan. 1994. Molecular cloning, functional expression, tissue distribution, and in situ hybridization of the renal sodium phosphate $\left(\mathrm{Na}^{+} / \mathrm{Pi}\right)$ transporter in the control and hypophosphatemic mouse. FASEB. J. 8:862-868.

Cross, H. S., H. Debiec and M. Peterlik. 1990. Mechanism and regulation of intestinal phosphate absorption. Miner. Electrolyte Metab. 16:115-124.

Ghishan, F. K., N. Arab and H. Shibata. 1990. Intestinal phosphate transport in spontaneously hypertensive rats and genetically matched controls. Gastroenterology 99:106-112.

Hashimoto, M., D. Wang, T. Kamo, Y. Zhu, T. Tsujiuchi, Y. Konishi, M. Tanaka and H. Sugimura. 2000. Isolation and localization of type IIb $\mathrm{Na} / \mathrm{Pi}$ cotransporter in the developing rat lung. Am. J. Pathol. 157:21-27.

Hattenhaur, O., M. Traebert, H. Murer and J. Biber. 1999. Regulation of small intestinal Na-Pi type IIb cotransporter by dietary phosphate intake. Am. J. Physiol. Gasreoinrest. Liver Physiol. 277:G756-762.

Heaney, R.P. and B. E. C. Nordin. 2002. Calcium effects nn phnsphoius absorption:implications for the prevention and cotherapy of osteoporosis. J. Am. Coll. Nutr. 21:239-204.

Hector Giral, Yupanqui Caldas, Eileen Sutherland, Paul Wilson, Sophia Breusegem, Nicholas Barry, Judith Blaine, Tao Jiang, Xiaoxin X. Wang and Moshe Levi. 2009. Regulation of rat intestinal Na-dependent phosphate transporters by dietary phosphate. Am. J. Physiol. Renal Physiol. 297:1466-1475.

Hilfiker, H., O. Hattenhauer, M. Traebert, I. Forster, H. Murer and J. Biber. 1998. Characterization of a murine type II sodiumphosphate cotransporter expressed in mammalian intestine. Proc. Natl. Acad. Sci. USA. 95:14564-14569.

Huber, K., C. Walter, B. Schroder and G. Breves. 2002. Phosphate transport in the duodenum and jejunum of goats and its adaptation by dietary phosphate and calcium. Am. J. Physiol. Regul. Integr. Comp. Physiol. 283:R296-R302.

Hurwitz, S. and A. Bar. 1970. The sites of calcium and phosphate absorption in the chick. Poult. Sci. 49:324-325.

Kiyamova, R., V. Gryshkova, G. Ovcharenko and D. Lituyev et al. 2008. Development of monoclonal antibodis specific for the human sodium-dependent phosphate cotransporter NaPi2b. Hybridoma 27:277-284.

Magagnin, S., A. Werner, D. Markovich, V. Sorribas, G. Stange, J. Biber and H. Murer. 1993. Expression cloning of human and rat renal cortex Na/Pi cotransport. Proc. Natl. Acad. Sci. USA. 90:5979-5983.

McHaffie, G. S., C. Graham, B. Kohl, U. Strunck-Warnecke and A. Werner. 2007. The role of an intracellular cysteine stretch in the sorting of the type II Na/phosphate cotransporter. Biochim. Biophys. Acta. 1768:2099-2106.

Miyamoto, K., S. Tatsumi, T. Sondoda, H. Yamamoto, H. Minami, Y. Taketani and E. Takeda. 1995. Cloning and functional expression of a Na-dependent phosphate cotransporter from human kidney: cDNA cloning and functional expression. Biochem. J. 301:81-85.

Murer, H., I. Forster and J. Biber. 2004. The sodium phosphate cotransporter family SLC34. Pflugers. Arch. 447:763-767.

Nakagawa, N. and F. K. Ghishan. 1994. Low phosphate diet upregulates the renal and intestinal sodium-dependent phosphate transporter in vitamin D-resistant hypophosphatemic mice. Proc. Soc. Exp. Biol. Med. 205:162167.

Palmada, M., M. Dieter, A. Speil, C. Bohmer, A. F. Mack, H. J. Wagner, K. Klingel, R. Kandolf, H. Murer, J. Biber, E. I. Closs and F. Lang. 2004. Regulation of intestinal phosphate cotransporter NaPi IIb by ubiquitin ligase Nedd4-2 and by serum- and glucocorticoid-dependent kinase 1. Am. J. Physiol. Gastrointest. Liver Physiol. 287:G143-G150.

Quamme, G. A. 1985. Phosphate transport in intestinal brushborder membrane vesicles: effect of $\mathrm{pH}$ and dietary phosphate. Am. J. physiol. 249:G168-G176.

Radanovic, T., C. A. Wagner, H. Murer and J. Biber. 2005. Regulation of intestinal phosphate transport. I. Segmental expression and adaptation to low-P (i) diet of the type IIb Na+Pi cotransporter in mouse small intestine. Am. J. Physiol. 288:G496-G500.

Saddoris, K. L., J. C. Fleet and J. S. Radcliffe. 2010. Sodiumdependent phosphate uptake in the jejunum is posttranscriptionally regulated in pigs fed a low-phosphorus diet and is independent of dietary calcium concentration. J. Nutr. 4:731-736.

Segawa, H., I. Kaneko, S. Yamanaka, M. Ito, M. Kuwahata, Y. Inoue, S. Kato and K. Miyamoto. 2004. Intestinal Na-Pi cotranspotter adaptation to dietuy $\mathrm{Pi}$ content in vitamin D receptor null mice. Am. J. Physiol. Renal Physiol. 287:F39-47. Sugiura, S. H., K. Kelsey and R. P. Ferraris. 2007. Molecular and 
conventional responses of large rainbow trout to dietary phosphorus restriction. J. Comp. Physiol. B. 177:461-472.

Villa-Bellosta, R. and V. Sorribas. 2010. Compensatory regulation of the sodium/phosphate cotransporters NaPi-IIc (SCL34A3) and Pit-2 (SLC20A2) during Pi deprivation and acidosis. Pflugers. Arch. 459:499-508.
Xu, H., L. Bai, J. F. Collins and F. K. Ghishan. 2002. Agedependent regulation of rat intestinal type IIb sodiumphosphate cotransporter by 1, 25-(OH) 2 vitamin D3. Am. J. Physiol. Cell Physiol. 282:C487-C493.

Yan, F., R. Angel and C. M. Ashwell. 2007. Characterization of the chicken small intestine type IIb sodium phosphate cotransporter. Poult. Sci. 86:67-76. 